\title{
Effect of pirfenidone on breathlessness in patients with idiopathic pulmonary fibrosis
}

\author{
To the Editor:
}

Dyspnoea is a frequent and debilitating symptom in patients with idiopathic pulmonary fibrosis (IPF) and is reported as the most important factor determining their health-related quality of life (QoL) [1-3]. Previous post hoc analysis of pooled data from IPF clinical trials has shown that a worsening of dyspnoea was particularly likely in patients with more severe versus less severe disease [4]. Interestingly, it has been suggested that patients with more severe disease may experience a greater benefit from pirfenidone on categorical worsening of dyspnoea or death compared with patients with less severe disease [4]. Here, we report the results of a post hoc analysis aiming to further examine the effect of pirfenidone compared with placebo on dyspnoea severity in patients with IPF, including the change from baseline in dyspnoea over 12 months and categorical changes in dyspnoea at 12 months.

This post hoc analysis included all patients randomised to treatment with pirfenidone $2403 \mathrm{mg} \cdot \mathrm{day}^{-1}$ or placebo in the ASCEND (study 016, NCT01366209) [5] and CAPACITY (studies 004 and 006, NCT00287716 and NCT00287729) [6] phase III clinical trials who completed the University of California, San Diego Shortness of Breath Questionnaire (UCSD SOBQ) at baseline. Patients were pooled and stratified by baseline Gender, Age, Physiology (GAP) stage I versus stage II/III and by baseline forced vital capacity (FVC) $\geqslant 80 \%$ versus $<80 \%$. Patients completed the UCSD SOBQ at 12 -week (CAPACITY) or 13-week (ASCEND) intervals and outcomes were assessed up to week 52 [7]; higher scores indicated more breathlessness [1].

Changes in UCSD SOBQ score were compared using the Hodges-Lehmann estimate of the median differences between treatment groups in changes from baseline to month 12 with 95\% confidence intervals. Missing data were imputed using the sum of squared differences (SSD) method; deaths were assigned the highest UCSD SOBQ score of 120 points. Categorical changes in UCSD SOBQ score of $<0$, $0-<10,10-<20,20-<30$ and $\geqslant 30$ points were also considered and compared using the Mantel-Haenszel Chi-squared test. Percentages of patients with a change of $\geqslant 5, \geqslant 10$ or $\geqslant 20$ UCSD SOBQ points or death at month 12 were summarised and compared using a Chi-squared test. Missing data were imputed using the SSD method; deaths were added to the group with the highest categorical change in UCSD SOBQ.

In total, 1234 patients were included in this post hoc analysis (pirfenidone $\mathrm{n}=617$, placebo $\mathrm{n}=617$ ). Baseline data for this population have been previously reported [4, 7]. In patients with GAP stage II/III, those who received pirfenidone reported a significantly lower median change in UCSD SOBQ score from baseline to month 12 compared with placebo (9.2 versus 13.0 points, respectively; $p=0.009$ ) (figure 1a). A significantly lower median change in UCSD SOBQ score from baseline to month 12 was also observed in patients with percent predicted $\mathrm{FVC}<80 \%$ who received pirfenidone compared with placebo (8.5 versus 12.0 points, respectively; $\mathrm{p}=0.006$ ) (figure $1 \mathrm{~b}$ ). There were no significant differences in changes observed from baseline to month 12 in patients with GAP stage I or percent predicted FVC $\geqslant 80 \%$ who received pirfenidone compared with placebo.

There was a significant difference between the pirfenidone and placebo groups for the categorical change in UCSD SOBQ score from baseline at 12 months in both the GAP stage II/III ( $p=0.013$ ) (figure $1 \mathrm{c}$ ) and percent predicted $\mathrm{FVC}<80 \%$ ( $\mathrm{p}=0.005$ ) (figure 1d) groups. In both these groups, a greater percentage of

@ERSpublications

New post hoc analysis of IPF clinical trials suggests that treatment with pirfenidone slows the worsening of patient-reported breathlessness over 12 months versus placebo in patients with more advanced disease (GAP stage II/III or FVC $<\mathbf{8 0} \%$ ) http://bit.ly/2yJyUVT

Cite this article as: Glassberg MK, Wijsenbeek MS, Gilberg F, et al. Effect of pirfenidone on breathlessness in patients with idiopathic pulmonary fibrosis. Eur Respir J 2019; 54: 1900399 [https://doi. org/10.1183/13993003.00399-2019]. 
a)

GAP stage I

GAP stage II/III

\begin{tabular}{|l|c|c|c|c|}
\hline $\begin{array}{l}\text { UCSD SOBQ } \\
\text { at 12 months }\end{array}$ & $\begin{array}{c}\text { Pirfenidone } \\
(\mathbf{n = 2 4 2 )}\end{array}$ & $\begin{array}{c}\text { Placebo } \\
(\mathbf{n}=\mathbf{2 3 4})\end{array}$ & $\begin{array}{c}\text { Pirfenidone } \\
(\mathbf{n}=\mathbf{3 7 5})\end{array}$ & $\begin{array}{c}\text { Placebo } \\
\text { (n=381) }\end{array}$ \\
\hline $\begin{array}{l}\text { Score at baseline, } \\
\text { median (IQR) }\end{array}$ & $\begin{array}{c}28.9 \\
(13.5-44.0)\end{array}$ & $\begin{array}{c}30.4 \\
(16.0-48.0)\end{array}$ & $\begin{array}{c}33.4 \\
(19.5-51.0)\end{array}$ & $\begin{array}{c}32.5 \\
(19.0-51.1)\end{array}$ \\
\hline $\begin{array}{l}\text { Median change } \\
\text { from baseline }\end{array}$ & 5.0 & 3.3 & 9.2 & 13.0 \\
\hline $\begin{array}{l}\text { HL median difference } \\
\text { in change (95\% CI) }\end{array}$ & $\begin{array}{r}0.11(-2.50-3.00) \\
\mathrm{p}=0.852\end{array}$ & $\begin{array}{c}-3.67(-6.50--1.00) \\
\mathrm{p}=0.009\end{array}$ \\
\hline
\end{tabular}

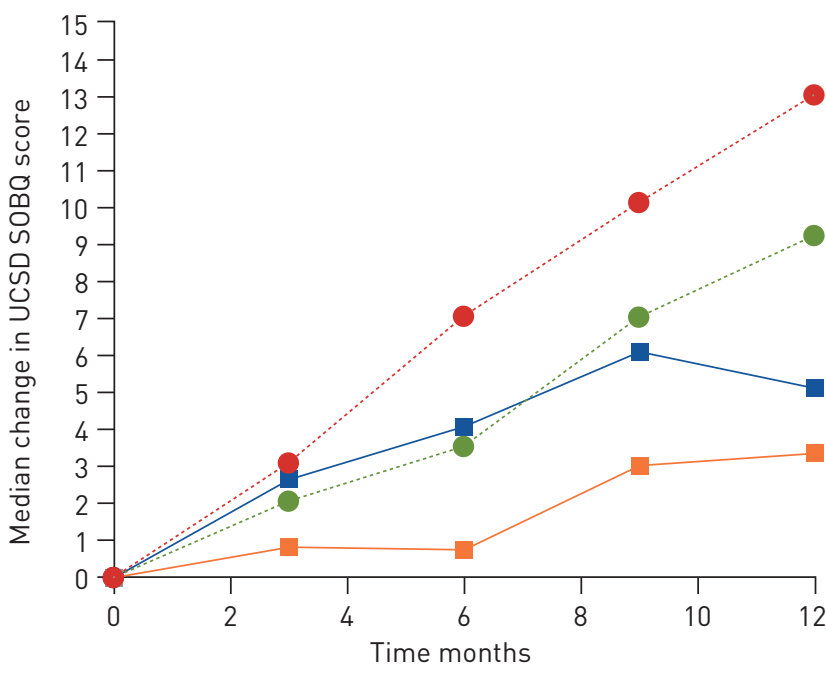

GAP stage I — Pirfenidone $2403 \mathrm{mg} \cdot \mathrm{day}^{-1} \longrightarrow$ Placebo GAP stage II/III ......... Pirfenidone $2403 \mathrm{mg} \cdot$ day $^{-1} \quad$....... Placebo

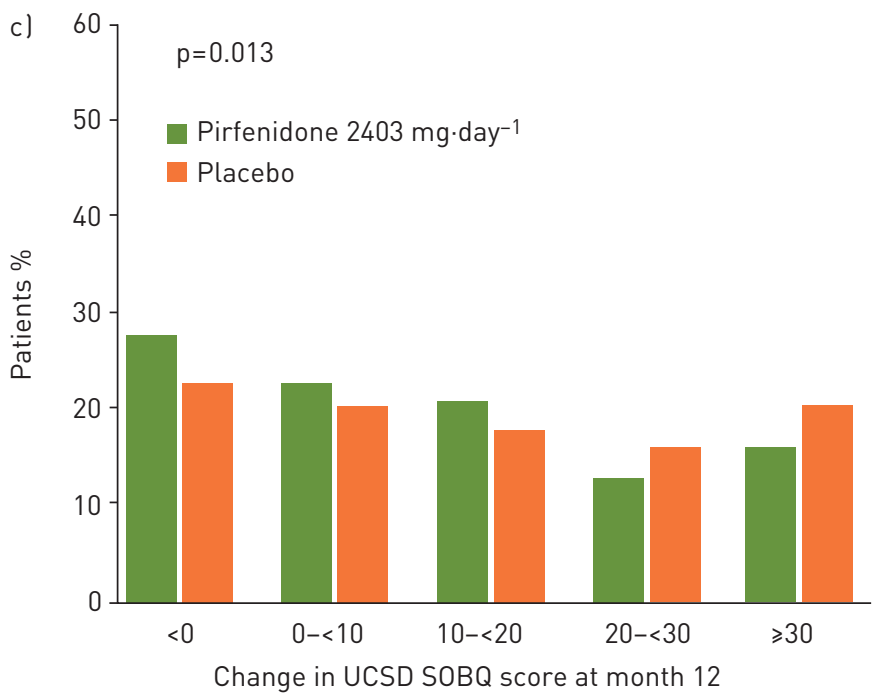

b)

$\% \mathrm{FVC} \geqslant 80 \% \quad \% \mathrm{FVC}<80 \%$

\begin{tabular}{|l|c|c|c|c|}
\hline $\begin{array}{l}\text { UCSD SOBQ } \\
\text { at 12 } \text { months }\end{array}$ & $\begin{array}{c}\text { Pirfenidone } \\
(\mathbf{n}=144)\end{array}$ & $\begin{array}{c}\text { Placebo } \\
(\mathbf{n}=167)\end{array}$ & $\begin{array}{c}\text { Pirfenidone } \\
(\mathbf{n}=\mathbf{4 7 3 )}\end{array}$ & $\begin{array}{c}\text { Placebo } \\
(\mathbf{n}=\mathbf{4 5 0 )}\end{array}$ \\
\hline $\begin{array}{l}\text { Score at baseline, } \\
\text { median (IQR) }\end{array}$ & $\begin{array}{c}25.0 \\
(10.0-43.6)\end{array}$ & $\begin{array}{c}29.0 \\
(15.0-44.0)\end{array}$ & $\begin{array}{c}33.0 \\
(19.0-50.0)\end{array}$ & $\begin{array}{c}32.0 \\
(18.5-51.1)\end{array}$ \\
\hline $\begin{array}{l}\text { Median change } \\
\text { from baseline }\end{array}$ & 4.1 & 4.0 & 8.5 & 12.0 \\
\hline $\begin{array}{l}\text { HL median difference } \\
\text { in change (95\% CI) }\end{array}$ & \multicolumn{2}{|c|}{$\begin{array}{c}0.18(-3.00-3.50) \\
\mathrm{p}=0.876\end{array}$} & $\begin{array}{c}-3.50(-6.00--1.00) \\
\mathrm{p}=0.006\end{array}$ \\
\hline
\end{tabular}
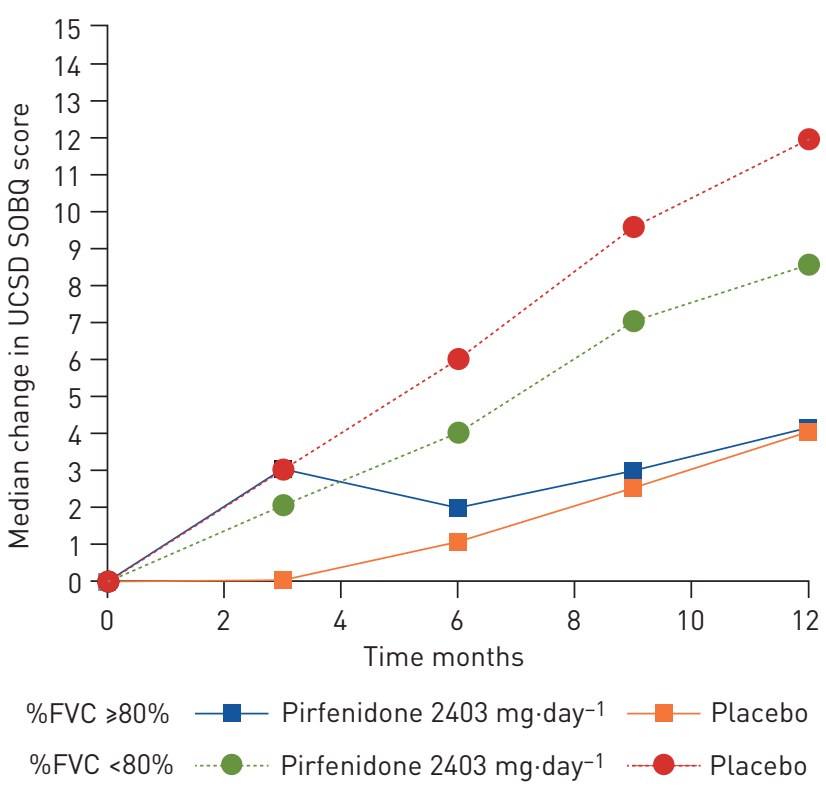

d)

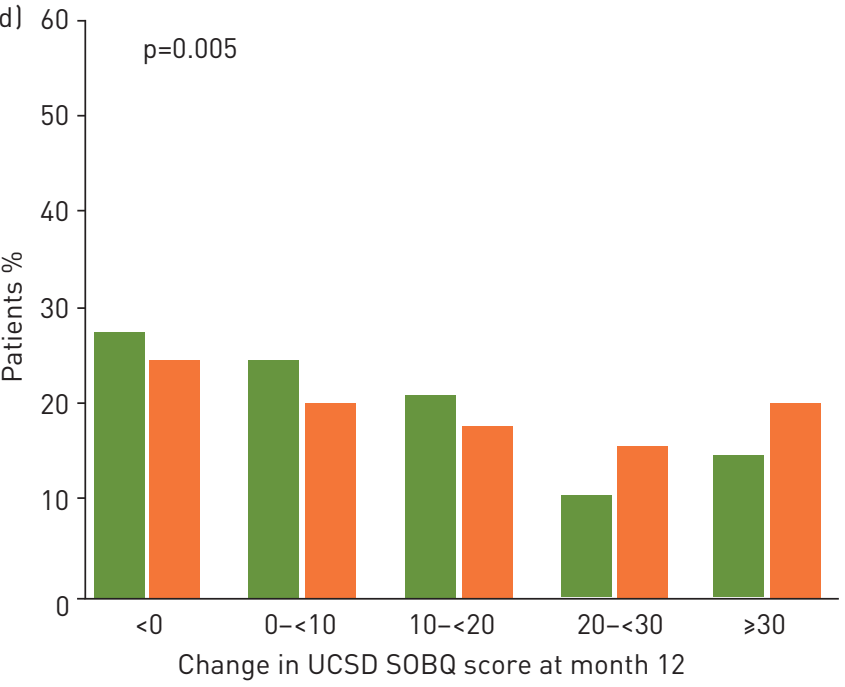

FIGURE 1 Median change in University of California, San Diego Shortness of Breath Questionnaire (UCSD SOBQ) scores from baseline over time in patients with a) Gender, Age, Physiology (GAP) stage I versus GAP stage II/III and b) percent predicted forced vital capacity (FVC) $\geqslant 80 \%$ versus $<80 \%$. Missing values were imputed using the sum of squared differences method. Deaths were imputed to a score of 120 points and $p$-values are for the Wilcoxon two-sample test. Categorical changes in UCSD SOBQ scores in patients with c) GAP stage II/III ( $n=375$ pirfenidone, $n=381$ placebo) and d) \%FVC <80\% ( $n=473$ pirfenidone, $n=450$ placebo). Missing values were imputed using the sum of squared differences method. Deaths were assigned to the group with a $\geqslant 30$-point change in UCSD SOBQ at month 12. $p$-values are for pirfenidone versus placebo across categories (Mantel-Haenszel Chi-squared test). HL: Hodges-Lehmann; IQR: interquartile range.

patients treated with pirfenidone were in the $<0,0-10$ and $10-<20$ categories of change in UCSD SOBQ score compared with placebo, while a greater percentage of placebo patients were in the $20-<30$ and $\geqslant 30$ categories compared with pirfenidone (figures $1 \mathrm{c}$ and $\mathrm{d}$ ). In patients with GAP stage I or percent predicted FVC $\geqslant 80 \%$, no significant differences in categorical changes in UCSD SOBQ scores from baseline were observed at month 12 in patients who received pirfenidone compared with placebo. 
This post hoc analysis showed that pirfenidone reduced the worsening of patient-reported breathlessness in patients with percent predicted FVC $<80 \%$ and/or those with GAP stage II/III, and that this effect was evident over the full 12-month treatment period. These findings are important because dyspnoea is one of the most debilitating symptoms of IPF and negatively impacts patients' QoL $[1,8]$. Furthermore, based on a minimum clinically important difference of 8 points in UCSD SOBQ score estimated using data from patients with more advanced IPF in the STEP-IPF trial of sildenafil [1], the change in UCSD SOBQ scores seen in the placebo arm of our analyses for GAP stage II/III or percent predicted FVC $<80 \%$ represented a clinically significant deterioration.

The effect of pirfenidone on dyspnoea was only observed in patients with greater lung function impairment (percent predicted FVC $<80 \%$ ) or those with GAP stage II/III. Dyspnoea was not specifically assessed in the INPULSIS trials of nintedanib, making direct comparisons challenging [9]; however, QoL was assessed across patient subgroups (percent predicted FVC $\leqslant 70 \%$ and $>70 \%$ ) using the St George's Respiratory Questionnaire and similar findings were observed [10]. The absence of effect in the group of patients with less advanced disease is similar to the results presented in this subgroup analysis.

In daily clinical practice, there is sometimes hesitation to start antifibrotic treatment in patients with IPF who have less advanced disease or who are asymptomatic [11]. Although a treatment benefit on dyspnoea was not observed in patients with FVC $\geqslant 80 \%$ or GAP stage I, pirfenidone has been shown to have equally beneficial effects on disease progression end-points, including FVC or death, in these subgroups [4]. Importantly, analysis of data from the open-label, long-term extension study of the ASCEND and CAPACITY trials (RECAP) showed that patients treated with placebo in CAPACITY experienced a reduction in the annual rate of lung function decline once pirfenidone was initiated. However, the lung function lost while they received placebo was not recovered once pirfenidone treatment was started [12]. The available data underline the unmet need to begin treatment in a timely manner and reduce the rate of further lung function decline $[4,13]$.

There are a number of limitations to this analysis, including its post hoc nature and that the analysis was not powered to assess differences in efficacy outcomes by different stages of lung function. In addition, it is likely that the ASCEND and CAPACITY population had less severe dyspnoea than might be expected in a real-world population. For example, the INSIGHTS-IPF registry reported much higher UCSD SOBQ scores at baseline [14] than were reported in the pirfenidone trials, which may be due to the exclusion criteria for those trials.

In conclusion, these results suggest that treatment with pirfenidone slowed the worsening of patient-reported breathlessness over 12 months versus placebo in patients with GAP stage II/III or percent predicted FVC $<80 \%$. Further research is needed to examine the effects of pirfenidone on IPF-related symptoms including dyspnoea in real-world populations. There is also a need to confirm if the change in UCSD SOBQ over time is valid in a real-world population of patients with IPF.

Marilyn K. Glassberg ${ }^{1}$, Marlies S. Wijsenbeek ${ }^{2}$, Frank Gilberg ${ }^{3}$, Ute Petzinger ${ }^{4}$, Klaus-Uwe Kirchgaessler ${ }^{3}$ and Carlo Albera ${ }^{5}$

${ }^{1}$ Miller School of Medicine, University of Miami, Miami, FL, USA. ${ }^{2}$ Erasmus MC University Medical Center, Rotterdam, The Netherlands. ${ }^{3}$ F. Hoffmann-La Roche, Ltd., Basel, Switzerland. ${ }^{4}$ Accovion GmbH, Eschborn, Germany. ${ }^{5}$ School of Medicine, Dept of Medical Sciences, University of Turin, Turin, Italy.

Correspondence: Marilyn K. Glassberg, Miller School of Medicine, University of Miami, 1600 NW 10th Avenue, Miami, FL 33136, USA. E-mail: mglassbe@med.miami.edu

Received: 08 Oct 2018 | Accepted after revision: 13 May 2019

Acknowledgements: Medical writing support was provided by Ceilidh McConnachie (CMC AFFINITY, a division of McCann Health Medical Communications Ltd, Glasgow, UK), funded by Genentech, Inc. and F. Hoffmann-La Roche, Ltd.

Data sharing: Qualified researchers may request access to individual patient level data through the clinical study data request platform (www.clinicalstudydatarequest.com). Further details on Roche's criteria for eligible studies are available here: https://clinicalstudydatarequest.com/Study-Sponsors/Study-Sponsors-Roche.aspx. For further details on Roche's Global Policy on the Sharing of Clinical Information and how to request access to related clinical study documents, see: www.roche.com/research_and_development/who_we_are_how_we_work/clinical_trials/our_commitment_to_data_ sharing.htm.

Author contributions: F. Gilberg, U. Petzinger and K-U. Kirchgaessler were involved in the design of this analysis. F. Gilberg and U. Petzinger were involved in the analysis of data. All authors were involved in drafting and revising the research letter, and provided final approval of the version to be published. All authors vouch for the accuracy of the content included in the final research letter. 
Support statement: This analysis was sponsored by Genentech, Inc. and F. Hoffmann-la Roche, Ltd. Funding information for this article has been deposited with the Crossref Funder Registry.

Conflict of interest: M.K. Glassberg reports grants and/or consultancy or steering fees from Genentech, Inc., Boehringer Ingelheim, Patara Pharma and Bellerophon Therapeutics, outside the submitted work. M.S. Wijsenbeek reports grants and/or fees from F. Hoffman-la Roche, Ltd, Boehringer Ingelheim and Galapagos, outside the submitted work. All fees were paid to her institution. F. Gilberg is an employee of F. Hoffmann-la Roche, Ltd and may hold shares. U. Petzinger was an employee of Clinipace-Accovion GmbH (a company contracted by F. Hoffmann-la Roche, Ltd to perform analyses of study data) at the time of this study. K-U. Kirchgaessler is an employee of F. Hoffmann la Roche, Ltd and may hold shares. C. Albera reports personal fees from FibroGen, Bayer, Boehringer Ingelheim, GlaxoSmithKiine, lnterMune/Roche, MSD, Sanofi and F. Hoffmann-la Roche, Ltd, outside the submitted work.

\section{References}

1 Swigris JJ, Han M, Vij R, et al. The UCSD shortness of breath questionnaire has longitudinal construct validity in idiopathic pulmonary fibrosis. Respir Med 2012; 106: 1447-1455.

2 Nishiyama O, Taniguchi $\mathrm{H}$, Kondoh $\mathrm{Y}$, et al. Health-related quality of life in patients with idiopathic pulmonary fibrosis. What is the main contributing factor? Respir Med 2005; 99: 408-414.

3 Hewson T, McKeever TM, Gibson JE, et al. Timing of onset of symptoms in people with idiopathic pulmonary fibrosis. Thorax 2018; 73: 683-685.

4 Albera C, Costabel U, Fagan EA, et al. Efficacy of pirfenidone in patients with idiopathic pulmonary fibrosis with more preserved lung function. Eur Respir J 2016; 48: 843-851.

5 King TE Jr, Bradford WZ, Castro-Bernardini S, et al. A phase 3 trial of pirfenidone in patients with idiopathic pulmonary fibrosis. N Engl J Med 2014; 370: 2083-2092.

6 Noble PW, Albera C, Bradford WZ, et al. Pirfenidone in patients with idiopathic pulmonary fibrosis (CAPACITY): two randomised trials. Lancet 2011; 377: 1760-1769.

7 Noble PW, Albera C, Bradford WZ, et al. Pirfenidone for idiopathic pulmonary fibrosis: analysis of pooled data from three multinational phase 3 trials. Eur Respir J 2016; 47: 243-253.

8 American Thoracic SocietyEuropean Respiratory Society. American Thoracic Society/European Respiratory Society International Multidisciplinary Consensus Classification of the Idiopathic Interstitial Pneumonias. This joint statement of the American Thoracic Society (ATS), and the European Respiratory Society (ERS) was adopted by the ATS board of directors, June 2001 and by the ERS Executive Committee, June 2001. Am J Respir Crit Care Med 2002; 165: 277-304.

9 Richeldi L, du Bois RM, Raghu G, et al. Efficacy and safety of nintedanib in idiopathic pulmonary fibrosis. $N$ Engl J Med 2014; 370: 2071-2082.

10 Costabel U, Inoue Y, Richeldi L, et al. Efficacy of nintedanib in idiopathic pulmonary fibrosis across prespecified subgroups in INPULSIS. Am J Respir Crit Care Med 2016; 193: 178-185.

11 Maher TM, Swigris JJ, Kreuter M, et al. Differences in patient and physician viewpoints of the management of idiopathic pulmonary fibrosis (IPF). Am J Respir Crit Care Med 2017; 195: A1123.

12 Maher TM, Jouneau S, Morrison L, et al. Deferring treatment with pirfenidone results in loss of lung function that is not recovered by later treatment initiation. Thorax 2017; 72: A251-A252.

13 Maher TM, Molina-Molina M, Russell AM, et al. Unmet needs in the treatment of idiopathic pulmonary fibrosis-insights from patient chart review in five European countries. BMC Pulm Med 2017; 17: 124.

14 Kreuter M, Swigris J, Pittrow D, et al. Health related quality of life in patients with idiopathic pulmonary fibrosis in clinical practice: insights-IPF registry. Respir Res 2017; 18: 139. 